\title{
SOSIALIASI PROGRAM KERJA KELOMPOK KKN DALAM MENGUBAH PENGETAHUAN EKONOMI MASYARAKAT KELURAHAN DODU
}

\author{
SOCIALIZATION OF THE COMMUNITY GROUP'S WORK PROGRAM \\ IN CHANGING THE ECONOMIC KNOWLEDGE \\ OF THE DODU SHARE COMMUNITY
}

\author{
Puji Muniarty ${ }^{*}$, Wulandari, Tauhid Lil Akbar, Esiati, Muhamad Ridwan \\ Sekolah Tinggi Ilmu Ekonomi (STIE) Bima \\ Jln. Wolter Monginsidi Kompleks Tolobali Kota Bima, NTB \\ *Email : puji.stiebima@gmail.com \\ (Diterima 01-09-2021; Disetujui 24-09-2021)
}

\begin{abstract}
ABSTRAK
Kelurahan Dodu dengan potensi sumber daya alam khususnya pertanian dan perkebunan menjadi daya tarik ekonomis untuk menambah penghasilan masyarakat. Selama ini masyarakat belum terbiasa memanfaatkan limbah rumah tangga maupun potensi sumber daya sekitar untuk menghasilkan produk yang lebih bernilai ekonomis. Secara ekonomis masih kurangnya inovasi produk dari masyarakat, adanya potensi wisata yang belum dikembangkan oleh masyarakat. Tujuan kegiatan pengabdian kepada masyarakat melalui seminar program kerja ini diharapkan penggalian potensi dan daya ungkit ekonomi wilayah bisa lebih dikembangkan oleh masyarakat khususnya di Kelurahan Dodu. Metode yang digunakan dalam kegiatan pengabdian kepada masyarakat oleh mahasiswa KKN STIE Bima dibagi menjadi tiga tahap yaitu; tahap pendekatan, tahap pelaksanaan, tahap monitoring dan evaluasi. uraian program kerja oleh mahasiswa KKN STIE BIMA yang terdiri atas tiga agenda utama, yaitu: pengelolaan buah pinang, telur asin dan diversifikasi produk rengginang, pengembangan potensi wisata La satu sebagai salah satu ikon, dan pemanfaatan limbah air beras sebagai pupuk cair. Melalui peningkatan pengetahuan masyarakat untuk diversifikasi potensi produk lokal sehingga menjadi produk yang lebih bernilai ekonomis melalui sosialisai program kerja oleh mahasiswa KKN STIE Bima.
\end{abstract}

Kata kunci: Kuliah Kerja Nyata, Program Kerja, Sosialisasi

\section{ABSTRACT}

Dodu Village with its natural resource potential, especially agriculture and plantations, is an economic attraction to increase people's income. So far, people are not used to utilizing household waste and the potential of surrounding resources to produce products that have more economic value. Economically, there is still a lack of product innovation from the community, there is tourism potential that has not been developed by the community. The purpose of community service activities through this work program seminar is that it is hoped that the exploration of the potential and economic leverage of the region can be further developed by the community, especially in Dodu Village. The method used in community service activities by KKN STIE Bima students is divided into three stages, namely; Approach Phase, Implementation Phase, Monitoring and Evaluation Phase. The description of the work program by STIE BIMA KKN students which consists of three main agendas, namely; Management of areca nut, salted eggs and diversification of rengginang products, Development of tourism potential of La one as an icon, Utilization of rice water waste as liquid fertilizer. Through increasing public knowledge to diversify the potential of local products so that they become more economically valuable products through socialization of work programs by KKN STIE Bima students.

Keywords: Real Work Lecture, Work Program, Socialization

\section{PENDAHULUAN}

Kuliah Kerja Nyata (KKN) adalah kegiatan kurikuler mahasiswa program S1 tingkat akhir, yang dominan dilaksankan di luar kampus pada waktu tertentu yang mencakup kegiatan pengabdian kepada masyarakat seperti yang tercantum dalam tridharma 
Sosialiasi Program Kerja Kelompok KKN Dalam Mengubah Pengetahuan Ekonomi Masyarakat Kelurahan Dodu Puji Muniarty, Wulandari, Tauhid Lil Akbar, Esiati, Muhamad Ridwan

perguruan tinggi yang dilaksanakan secara intrerdisipliner dan lintas sektoral. Dengan lebih mengedepankan konsep kewirausahaan dalam konteks ekonomi, program garapan kegiatan KKN adalah program fisik dan non fisik seperti program seminar serta edukasi dan pengembangan potensi wisata. Program-program tersebut disesuaikan dengan keadaan lingkungan dimana tempat KKN berlangsung. Sejalan dengan Program Wira Desa sebagai konsep yang mengkolaborasikan masyarakat, lingkungan desa dan perguruan tinggi guna menumbuhkan dan mengembangkan kewirausahaan desa yang tidak terlepas dari berbagai problem dalam penggelolaan dan pengembangan produk unggul desa (Muniarty, 2021).

Pengabdian kepada masyarakat merupakan salah satu komponen kegiatan akademik yang merupakan bagian dari tri dharma perguruan tinggi, disamping pendidikan dan penelitian. Dengan dilaksanakannya dharma pengabdian kepada masyarakat disamping kedua dharma yang lain, diharapkan selalu ada interelasi antara perguruan tinggi dan masyarakat sekitarnya. Kegiatan pengabdian kepada masyarakat sebagai tindakan nyata melalui penguatan kapasitas masyarakat agar lebih berdaya baik dari segi partisipasi maupun penguatan kapasitas nya. Aspek ekonomis mengarah kepada meningkatkan nilai jual produk dan pemanfaatan limbah rumah tangga yang terbuang percuma. Penyelenggaraan KKN tematik membangun desa bertujuan untuk membangun kesadaran kritis masyarakat dalam rangka membangun komunitas (desa) yang lebih partisipatif dan mampu menemukan gagasan-gagasan kreatif untuk memecahkan masalah desanya (Sadapotto, 2020).

Kelurahan Dodu berada di Kecamatan Rasanae Timur Kota Bima. Penduduk setempat umumnya bermata pencarian sebagai petani, wiraswasta dan sedikit sebagai Pegawai Negeri Sipil. Secara geografis, masyarakat Kelurahan Dodu seluruhnya beragama Islam dan keberagaman suku tidak berkembang dikarenakan tidak ada suku penduduk pendatang. Posisi strategi dengan potensi sumber daya alam khususnya pertanian dan perkebunan menjadi daya tarik ekonomis untuk menambah penghasilan masyarakat. Selama ini masyarakat belum terbiasa memanfaatkan limbah rumah tangga maupun potensi sumber daya sekitar untuk menghasilkan produk yang lebih bernilai ekonomis. Transfer pengetahuan tersebut terwujud dalam pendidikan ekonomi yang sifatnya informal (Hasan, 2018). Masyarakat lebih berdaya melalui pengembangan kapasistasnya.

Pengembangan masyarakat adalah proses yang ditujukan untuk menciptakan kemajuan sosial dan ekonomi masyarakat melalui partisipatif aktif serta inisiatif. Anggota masyarakat dipandang bukan sistem klien yang bermasalah, melainkan sebagai masyarakat yang unik dan memiliki potensi, hanya saja potensi tersebut belum sepenuhnya 
dikembangkan (Alfitri, 2011). Pengetahuan merupakan hasil "tahu" dan ini terjadi setelah orang mengadakan penginderaan terhadap suatu objek tertentu (Notoatmodjo,2010). Pengetahuan ekonomis sebagai output sosialisai program kerja yang dilaksanakan selama kegiatan Kuliah Kerja Nyata yaitu perubahan pola pikir masyarakat untuk lebih memanfaatkan sumberdaya alam sehingga bernilai lebih (Garlans, 2012). Output akhir melalui sosialisai program kerja yaitu masyarakat mengetahui dan mampu memanfaatkan pengetahuan yang diperoleh agar bermanfaat bagi kesejaheraan hidup.

Adapun beberapa permasalahan yang ditemukan selama obeservasi awal oleh mahasiswa di kelurahan Dodu, yaitu: masyarakat belum mampu mengembangkan suatu inovasi baru atau produk baru dengan memanfaatkan SDA yang ada, kurangnya inovasi produk dari masyarakat, adanya potensi wisata yang belum dikembangkan oleh masyarakat yaitu wisata La Satu, minimnya pengetahuan masyrakat terhadap UMKM. Melalui seminar program kerja ini diharapkan penggalian potensi dan daya ungkit ekonomi wilayah bisa lebih dikembangkan oleh masyarakat khususnya di Kelurahan Dodu.

\section{BAHAN DAN METODE}

Pelaksanaan kegiatan pengabdian masyarakat dibagi menjadi tiga tahap. Sejalan dengan kegiatan PKM ini dilaksanakan ke dalam bentuk pemaparan materi atau ceramah dan diskusi mengenai sosialisasi (Dwi, 2020). Metode yang digunakan dalam kegiatan pengabdian kepada masyarakat oleh mahasiswa KKN STIE Bima Angkatan-19 di kelurahan Dodu dijabarkan sebagai berikut:

- Tahap Pendekatan

Identifikasi potensi pemanfaatan sumber daya alam yang tersedia di kelurahan Dodu menjadi bernilai ekonomis. Membuat keputusan ekonomi yang cerdas adalah suatu pilihan, dan pilihan ini memerlukan upaya. Selain upaya, maka individu juga perlu memahami syarat-syarat yang tepat guna membuat keputusan ekonomi sehari-hari. Metode pedagogik yang diterapkan yaitu menggabungkan diseminasi teknologi dari mahasiswa dan kearifan lokal masyarakat dalam pemeliharaan ekologi. Pendekatan partisipatif oleh tim PKM kepada masyarakat kelurahan Dodu bertujuan untuk menarik minat dalam mengikuti pelatihan variasi produk, pengemasan dan sosialisasi pemasaran melalui media sosial.

- Tahap Pelaksanaan

Diawali dengan kegiatan persiapan, koordinasi pelaksanaan program selama 1 minggu antara tim mahasiswa KKN STIE Bima bersama lurah dan tokoh masyarakat Dodu. Pada tahap ini akan dilakukan observasi kegiatan identifikasi potensi dan 
pemanfaatan sumber daya alam serta kesiapan karang taruna guna koordinasi dengan mahasiswa kaitan teknis kegiatan kemasyarakatn di lokasi serta ketepatan penerapan teknologi sesuai potensi di lokasi.

Tahap pelaksanaan, program pendampingan dilaksanakan dalam tiga program kerja utama sesuai dengan kesepakatan bersama antara tim KKN STIE Bima dengan lurah, yaitu:

1. Pengelolaan buah pinang, telur asin dan diversifikasi produk rengginang.

2. Pengembangan potensi pariwisata La satu sebagai salah satu ikon dodu.

3. Pemanfaatan limbah air beras sebagai pupuk cair.

- Tahap monitoring dan evaluasi

Pendampingan dan penilaian atas capaian program yang telah dilaksanakan antara tim PKM terhadap masyarakat. Masyarakat sebagai mitra menyediakan lahan dan anggota wanita tani yang siap dilatih serta bersedia monitoring dan evaluasi, pendampingan dan penilaian atas capaian program yang telah dilaksanakan antara tim pungusul terhadap mitra.

\section{HASIL DAN PEMBAHASAN}

Seminar Program Kerja KKN bertujuan memperkenalkan masyarakat dengan programprogram KKN STIE BIMA sekaligus mendengarkan usulan program dari masyarakat. Sejalan dengan dengan pendapat Rachmat (2020) menyatakan seminar Program Kerja KKN tujuan dan manfaat memperkenalkan masyarakat dengan programprogram. Memberikan peluang untuk mahasiswa KKN STIE BIMA agar lebih dikenal oleh tokoh-tokoh masyarakat setempat diawal-awal masa KKN. Menurut Ansyarif, dkk menyatakan respon Lurah dan masyarakat dodu sangat menyambut baik pelaksanaan kegiatan seminar program kerja yang berlangsung di aula kelurahan Dodu pada Sabtu, 21 Agustus 2021 pukul 09.00 Wita-selesai. 


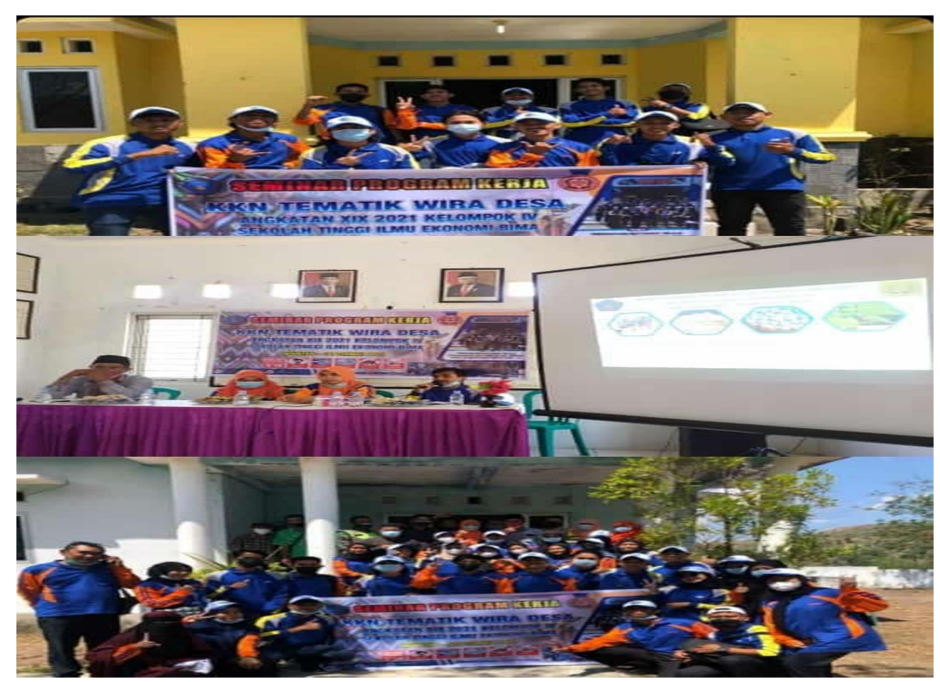

Gambar 1. Kegiatan sosialisasi program kerja

Berikut uraian program kerja oleh mahasiswa KKN STIE BIMA yang terdiri atas 3 agenda utama selain agenda mingguan yang dilaksanakan di lokasi KKN.

1. Pengelolaan buah pinang, telur asin dan diversifikasi produk rengginang.

Pemberdayaan merupakan upaya untuk membangun daya dengan mendorong, memberikan motivasi dan membangkitkan kesadaran akan potensi yang dimiliki serta untuk mengembangkan usaha (Wulandari, 2020). Proker ini didasari dengan melimpahnya arungginang, telur asin dan buah pinang di kelurahan Dodu. Pengembangan arungginang dan telur asin menjadi sebuah produk inovasi baru akan meningkatkan mutu dan harga jual dari arungginang dan telur asin itu sendiri. Selain itu, juga akan dapat menciptakan lapangan kerja baru bagi masyarakat Dodu. Sehingga melalui hal ini, tentu saja akan meningkatkan perekonomian masyarakat di kelurahan Dodu.

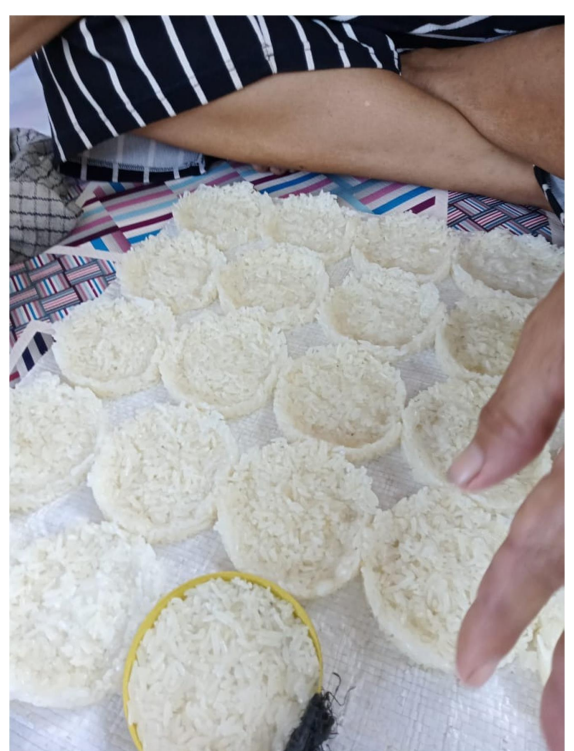

Produk sebelum diversifikasi

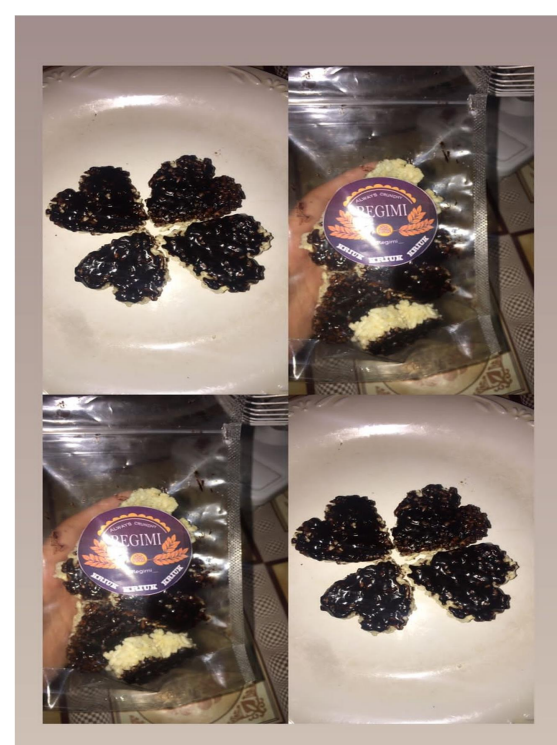

Dtampilan produk setelah diversifikasi Gambar 2. Diversifikasi produk olahan rengginang 
2. Pengembangan potensi wisata La satu sebagai salah satu ikon dodu.

Lasatu adalah salah satu sentral wisata yang ada di kelurahan dodu. Kelurahan Dodu adalah daerah yang memiliki sentral persawahan, maka dari itu kami juga memilih Lasatu ini menjadi objek wisata yang perlu dikembangkan karena belum adanya perhatian khusus masyarakat membuat wisata ini tidak dikenal banyak orang. Tujuan dari kegiatan ini adalah untuk menjadikan objek wisata Lasatu ini menjadi objek wisata yang popular, sehingga nantinya untuk memperbaiki perekonomian yang ada di kelurahan Dodu itu sendiri.
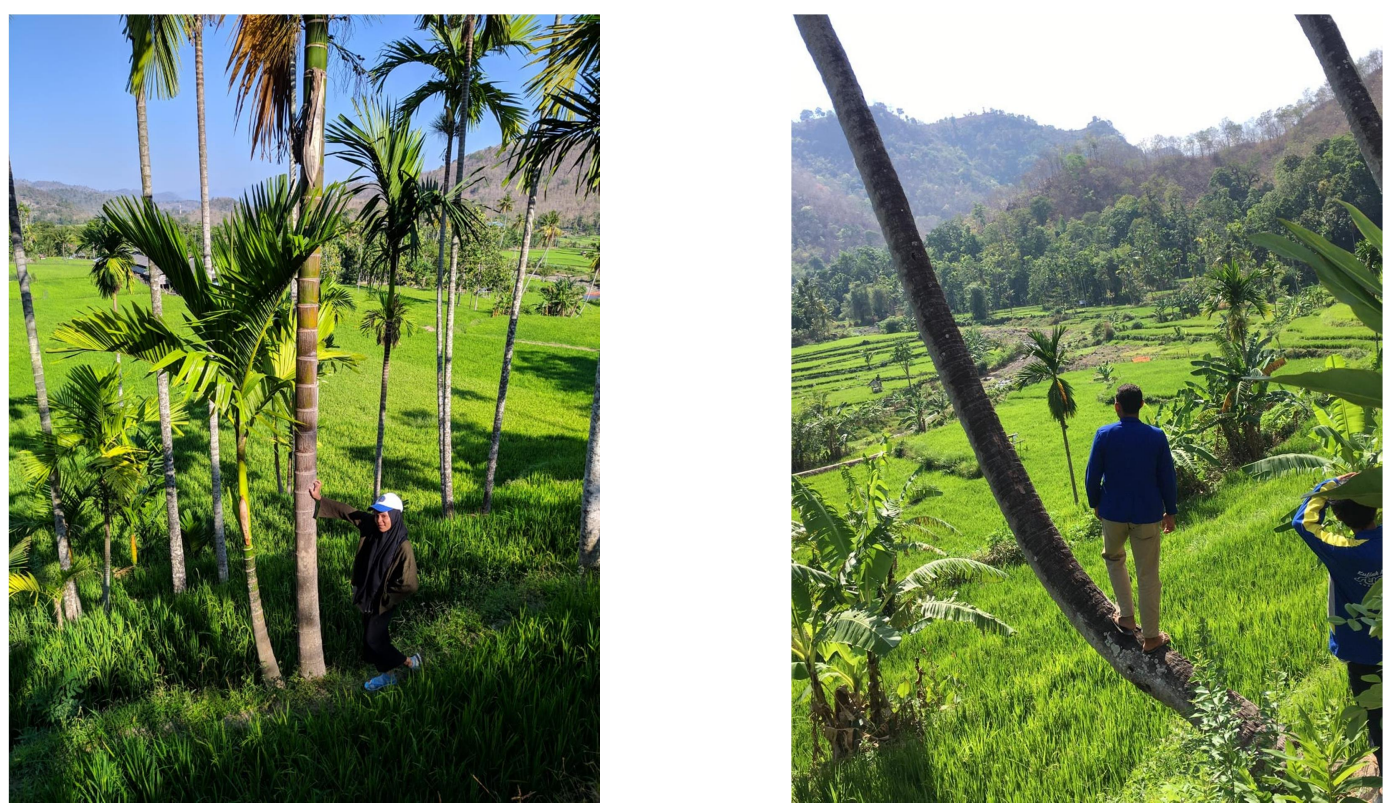

Gambar 3. Potensi wisata La Satu di Kelurahan Dodu

3. Pemanfaatan limbah air beras sebagai pupuk cair

Selaras dengan kondisi potensi Kelurahan Dodu sebagai sentra penghasil pangan, bagaimana kita bisa memanfaatkan limbah itu menjadi sebuah karya, maka dari itu kami mempunyai ide kreatif inovatif untuk menjadikan limbah air beras itu sebagai pupuk cair. Mungkin dengan adanya pupuk cair ini bisa memberikan dampak yang besar untuk sektor pertanian yang ada di kelurahan Dodu ini.

Selain ketiga proker utama, terdapat juga beberapa program harian dan mingguan sebagaimana disajikan dalam Tabel 1. 
Tabel 1. Program Harian KKN Kelurahan Dodu

\begin{tabular}{|c|c|c|c|c|}
\hline NO & SKEDUL KEGIATAN & TEMPAT & FASILITATOR & SASARAN \\
\hline 1 & $\begin{array}{l}\text { Pengembangan Kompetensi } \\
\text { Belajar membaca }\end{array}$ & Posko KKN & Bid. Kreatifitas & $\begin{array}{l}\text { Anak-Anak } \\
\text { Kelurahan } \\
\text { Dodu }\end{array}$ \\
\hline 2 & $\begin{array}{l}\text { Pengembangan kompetensi } \\
\text { belajar menggambar dan } \\
\text { mewarnai }\end{array}$ & Posko KKN & Bid. Kreatifitas & $\begin{array}{l}\text { Anak-Anak } \\
\text { Kelurahan } \\
\text { Dodu }\end{array}$ \\
\hline 3 & $\begin{array}{l}\text { Pengembangan kompetensi } \\
\text { belajar membaca Al-Qur'an }\end{array}$ & Posko KKN & Bid. Kerohanian & $\begin{array}{l}\text { Anak-Anak } \\
\text { Kelurahan } \\
\text { Dodu }\end{array}$ \\
\hline 4 & $\begin{array}{l}\text { Membantu kerjain PR dari } \\
\text { sekolah }\end{array}$ & Posko KKN & Bid. Kreatifitas & $\begin{array}{l}\text { Anak-Anak } \\
\text { Kelurahan } \\
\text { Dodu }\end{array}$ \\
\hline
\end{tabular}

Program harian ini merupakan kegiatan rutin secara terjadwal dan bergilir. Guna menunjang kegiatan KKN Mahasiswa STIE Bima, terdapat program mingguan yang terjadwal sebagai berikut;

Tabel 2. Program Mingguan KKN Kelurahan Dodu

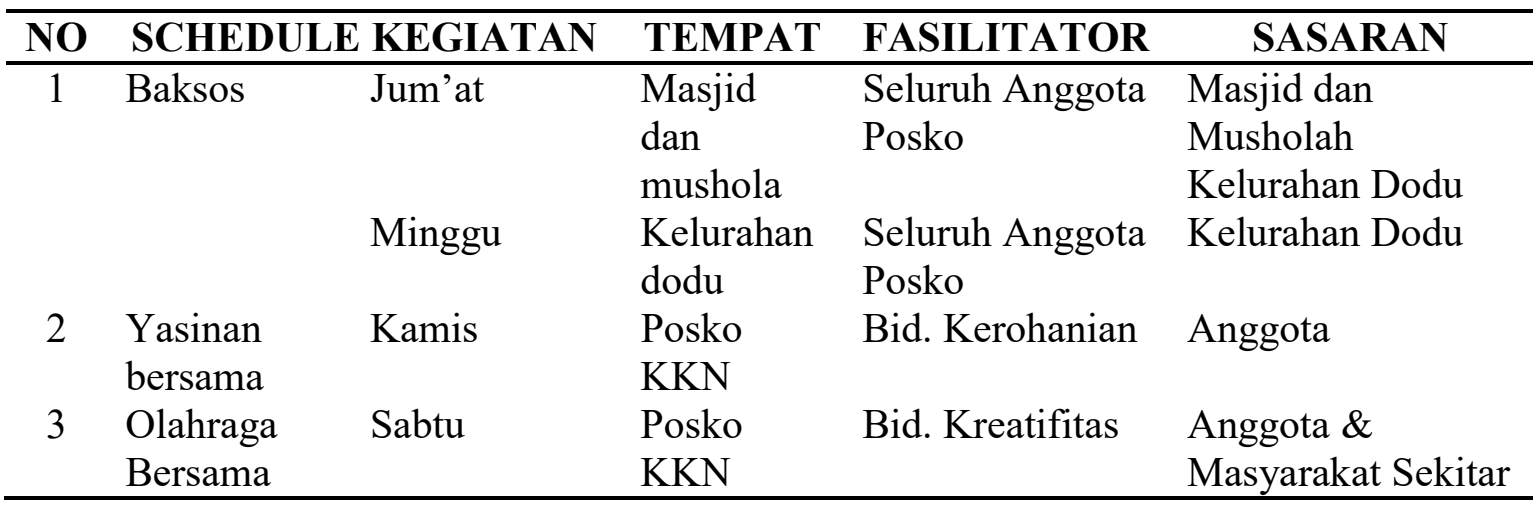

\section{KESIMPULAN DAN SARAN}

Kegiatan KKN STIE BIMA di Kelurahan Dodu secara umum adalah untuk mengamalkan tri dharma perguruan tinggi pada pilar pengabdian masyarakat. Secara khusus dimaksudkan agar terjadi peningkatan pemahaman terkait pemanfaatan potensi sumber daya alam agar bernilai ekonomis. Melalui peningkatan pengetahuan masyarakat untuk diversifikasi potensi produk lokal sehingga menjadi produk yang lebih bernilai ekonomis melalui sosialisai program kerja oleh mahasiswa KKN STIE Bima.

Berdasarkan uraian kesimpulan di atas, maka saran maka diperlukan pengabdian kepada masyarakat lebih lanjut lagi dengan melalui pembinaan proyek desa guna 
Sosialiasi Program Kerja Kelompok KKN Dalam Mengubah Pengetahuan Ekonomi Masyarakat Kelurahan Dodu

Puji Muniarty, Wulandari, Tauhid Lil Akbar, Esiati, Muhamad Ridwan

pengembangan produk unggulan desa yang lebih berkelanjutan dan dapat bermitra dengan pihak-pihak yang berkompeten dan membuat platform usaha melalui youtube.

\section{UCAPAN TERIMA KASIH}

Terimakasih kami sampaikan kepada Ketua dan seluruh CIvitas Akademika STIE BIMA, Lurah Dodu, tokoh masyarakat dan pemuda serta seluruh komponen masyarakat dan pihak-pihak lain yang telah membantu selama pelaksanaan kegiatan.

\section{DAFTAR PUSTAKA}

Alfitri. (2011). Community Development: Teori Dan Aplikasi. Yogyakarta: Pustaka Pelajar.

Dwi S. Y., S. L. (2020). SOSIALISASI DAN PELATIHAN FRAMEWORK CODELGNITER UNTUK SEKOLAH MENENGAH ATAS SYEKH YUSUF TANGERANG. KOMMAS: Jurnal Pengabdian Kepada Masyarakat Volume: 1 Nomor: 1., 161-167.

Garlans P., S. (2012). ANALISIS LITERASI EKONOMI. Jurnal Economia, Volume 8, Nomor 2, 135-143.

Hasan, M. (2018). PENDIDIKAN EKONOMI INFORMAL: BAGAIMANA PENDIDIKAN EKONOMI MEMBENTUK PENGETAHUAN PADA BISNIS KELUARGA? Jurnal Ekonomi dan Pendidikan Volume 1 Nomor 2 Juli, 30-37.

Muniarty P., Wulandari., Della S, Nur F., S., Wahdatul N. (2021). Sosialisasi Program Wira Desa Guna Mengembangkan Soft Skills Mahasiswa. JURPIKAT (Jurnal Pengabdian Kepada Masyarakat Vol. 2 No. 2, 1-9.

Notoatmodjo, S. (2010). Pendidikan dan Perilaku Kesehatan. Jakarta: Rineka Cipta.

Rachmat. (2020). IKHTIAR MAHASISWA KKN STIBA MAKASSAR DALAM PEMBENTUKAN AKHLAK QUR'ANI MASYARAKAT DESA BALASSUKA KABUPATEN GOWA. WAHATUL MUJTAMA': Jurnal Pengabdian Masyarakat Vol. 01, No. 1, 90-115.

Sadapotto, A. (2020). Sosialisasi Pembentukan Kelompok Tani Perempuan; Bentuk Integrasi KKN Dengan Pembangunan Desa Di Kecamatan Rumbia Kabupaten Jeneponto. Jurnal Pengabdian Masyarakat Hasanuddin (JPMH) Vol. 1 No.1 , 10-14.

Wulandari, Muniarty P. (2020). Pemberdayaan Petani Melalui Penguatan Kapasitas Penyuluhan di Kecamatan Rasanae Timur Kota Bima. Prosiding Seminar Nasional IPPeMas, 303-308. 